\title{
Experienced Quality of Post-Acute and Long-Term Care From the Care Recipient's Perspective-A Conceptual Framework
}

\author{
Citation for published version (APA): \\ Sion, K. Y. J., Haex, R., Verbeek, H., Zwakhalen, S. M. G., Odekerken-Schroder, G., Schols, J. M. G. A., \\ \& Hamers, J. P. H. (2019). Experienced Quality of Post-Acute and Long-Term Care From the Care \\ Recipient's Perspective-A Conceptual Framework. Journal of the American Medical Directors Association, \\ 20(11), 1386-1390. https://doi.org/10.1016/j.jamda.2019.03.028
}

Document status and date:

Published: 01/11/2019

DOI:

10.1016/j.jamda.2019.03.028

Document Version:

Publisher's PDF, also known as Version of record

\section{Document license:}

Taverne

Please check the document version of this publication:

- A submitted manuscript is the version of the article upon submission and before peer-review. There can be important differences between the submitted version and the official published version of record.

People interested in the research are advised to contact the author for the final version of the publication, or visit the DOI to the publisher's website.

- The final author version and the galley proof are versions of the publication after peer review.

- The final published version features the final layout of the paper including the volume, issue and page numbers.

Link to publication

\footnotetext{
General rights rights.

- You may freely distribute the URL identifying the publication in the public portal. please follow below link for the End User Agreement:

www.umlib.nl/taverne-license

Take down policy

If you believe that this document breaches copyright please contact us at:

repository@maastrichtuniversity.nl

providing details and we will investigate your claim.
}

Copyright and moral rights for the publications made accessible in the public portal are retained by the authors and/or other copyright owners and it is a condition of accessing publications that users recognise and abide by the legal requirements associated with these

- Users may download and print one copy of any publication from the public portal for the purpose of private study or research.

- You may not further distribute the material or use it for any profit-making activity or commercial gain

If the publication is distributed under the terms of Article $25 \mathrm{fa}$ of the Dutch Copyright Act, indicated by the "Taverne" license above, 
Special Article

\title{
Experienced Quality of Post-Acute and Long-Term Care From the Care Recipient's Perspective-A Conceptual Framework
}

\author{
Katya Y.J. Sion MSc ${ }^{\mathrm{a}, *}$, Roy Haex MSc, PDEng ${ }^{\mathrm{a}}$, Hilde Verbeek PhD ${ }^{\mathrm{a}}$, \\ Sandra M.G. Zwakhalen PhD, RN ${ }^{\mathrm{a}}$, Gaby Odekerken-Schröder $\mathrm{PhD}^{\mathrm{b}}$, \\ Jos M.G.A. Schols PhD, MD ${ }^{\mathrm{a}}$, Jan P.H. Hamers PhD, $\mathrm{RN}^{\mathrm{a}}$ \\ ${ }^{a}$ Department of Health Services Research, CAPHRI Care and Public Health Research Institute, Faculty of Health Medicine and Life Sciences, Maastricht \\ University, Maastricht, The Netherlands \\ ${ }^{\mathrm{b}}$ Department of Marketing and Supply Chain Management, SBE School of Business and Economics, Maastricht University, Maastricht, The Netherlands
}

Keywords:

Relationship-centered care experienced quality of care care recipient perspective caring relationships perceived outcomes quality framework

\begin{abstract}
A B S T R A C T
This article aims to conceptualize experienced quality of post-acute and long-term care for older people as perceived by care recipients. An iterative literature review and consultations with stakeholders led to the development of the INDividually Experienced QUAlity of Long-term care (INDEXQUAL) framework. INDEXQUAL presents the process of an individual care experience consisting of a pre (expectations), during (experiences), and post (assessment) phase. Expectations are formed prior to an experience by personal needs, past experiences, and word-of-mouth. An experience follows, which consists of interactions between the players in the caring relationships. Lastly, this experience is assessed by addressing what happened and how it happened (perceived care services), how this influenced the care recipient's health status (perceived care outcomes), and how this made the care recipient feel (satisfaction). INDEXQUAL can serve as a framework to select or develop methods to assess experienced quality of long-term care. It can provide a framework for quality monitoring, improvement, and transparency.
\end{abstract}

(c) 2019 AMDA - The Society for Post-Acute and Long-Term Care Medicine.
Long-term care (LTC) comprises a range of services to maintain or improve the functional and health outcomes of frail, chronically ill, and physically or cognitively disabled older people. ${ }^{1}$ LTC has been defined as "the activities undertaken by others to ensure that people with or at risk of a significant ongoing loss of intrinsic capacity can maintain a level of functional ability consistent with their basic rights, fundamental freedoms and human dignity," portraying the importance of relationships within this type of care delivery. ${ }^{2}$ LTC provision used to be considered a task-oriented, profession-driven service focused on safety and efficiency. ${ }^{3}$ Over the past decades, there

This study was funded by the 7 long-term care organizations belonging to the Living Lab in Aging and Long-Term Care (MeanderGroep, Cicero Zorggroep, Envida, Sevagram, Zuyderland, Mosae Zorggroep, and Vivantes); and the health insurance company CZ. They had no role in study design, data collection and analysis, decision to publish, or preparation of the manuscript.

The authors declare no conflicts of interest.

* Address correspondence to Katya Y.J. Sion, MSc, Department of Health Services Research, CAPHRI Care and Public Health Research Institute, Faculty of Health Medicine and Life Sciences, Maastricht University, Duboisdomein 30, 6229 GT, Maastricht, The Netherlands.

E-mail address: k.sion@maastrichtuniversity.nl (K.Y.J. Sion). has been an ongoing culture change striving toward a more holistic approach to care provision, incorporating not only the professional, but also the care recipient's, perspective, thus allowing more focus on the care recipient preferences, autonomy, and self-determination. ${ }^{4-7}$ This has resulted in the emerging need to define and assess quality of LTC as experienced by the care recipient.

In the mid-1960s, Donabedian already touched on the complexity of defining and assessing quality of care. ${ }^{8}$ He portrayed quality as a reflection of values and goals within the care system and society. Building on this, the Institute of Medicine ${ }^{9}$ defined quality of care as "the degree to which health services for individuals and populations increase the likelihood of desired health outcomes and are consistent with current professional knowledge." As quality of care consists of many aspects, it is challenging to assess and, therefore, indicators are often used to operationalize quality of care with Donabedian's structure-process-outcomes model, ${ }^{10}$ such as the prevalence of fall incidents, malnutrition, or pressure ulcers. ${ }^{11}$ Indicators, however, often focus on the physical aspects of care (ie, pressure ulcers), while underrepresenting the social (ie, engagement in daily life) and emotional aspects (ie, satisfaction) and ignoring others in the caring environment. $^{11-13}$ This is more in line with the professional or regulatory agency perspective, instead of representing the values 
and needs of what care recipients and their families find most important. ${ }^{1,14}$ This increasing focus on the care recipient's perspective has led to the development of quality indicators that can be assessed by the care recipients themselves by means of patient-reported outcome measures, including severity of pain and patient-reported experience measures such as the Consumer-Quality Index. ${ }^{15,16}$ Patient-reported outcome measures and patient-reported experience measures do not capture the care recipient's journey, which is important for establishing the experienced quality of care for an older person. ${ }^{17}$

Furthermore, from a service science perspective, care service delivery has certain characteristics that complicate the assessment of the experienced quality of care from the recipient's perspective. Care service delivery is characterized as being intangible, heterogeneous, perishable, interactive, and multifaceted. ${ }^{18,19}$ This means that the experience of care provision is built on interactions between people involved in a value-creating process, and, therefore, its quality cannot be judged in advance (intangible), it cannot be provided with uniformity (heterogeneous), and it cannot be stored; thus, the location and timing influence the experiences as well (perishability). Care provision is usually achieved during interactions between the care recipient and the care provider (interactive), and it is considered a complex service (multifaceted quality). The complexity of care services in combination with the more holistic view on (health) care and the increasing importance of the care recipient's perspective have resulted in the need for a clear understanding of the meaning of experienced quality of LTC.

\section{Conceptualization of Experienced Quality of LTC}

To conceptualize experienced quality of care, we performed multiple actions. The literature within the service sciences and health sciences was reviewed to identify models and frameworks defining the process of service quality from the user's perspective, and care quality from the care recipient's perspective. Iterative searches were performed in PubMed, PsycInfo, and EBSCO Business Source Complete, and by means of snowballing. We used search terms including "quality of care," "experienced quality," and "service quality." Based on identified relevant articles, we added search terms including "expectations," "perceived quality," "patient reported," and "satisfaction." We considered articles relevant if they presented a model, framework, concept, or theory related to experienced quality of LTC from the care recipient's perspective. Studies focused on the evaluation of an intervention or validation of an instrument were considered out of scope. In addition, the gray literature was searched to assure key publications were identified. Appendix 1 presents additional information on the article selection.

The identified models and frameworks were reviewed, compared with each other, and combined into a conceptual framework because existing models and frameworks did not fully fulfill the research aim to conceptualize experienced quality of LTC from the care recipient's perspective. This was an iterative process, during which results were reviewed, discussed, and adjusted in the research team. The research team consisted of a professor in care of older persons, a professor in old age medicine, a professor in nursing science, a professor in customer centric service science, an associate professor in LTC design, and 2 researchers with a background in psychology and health sciences. In addition, a panel of experts was assembled and gathered 3 times to reflect on the framework. This panel consisted of representatives from multiple national stakeholders in the Netherlands specialized in LTC policy, including the Ministry of Health $(\mathrm{n}=2)$, the National Health Care Institute $(\mathrm{n}=2)$, the National Client Council $(n=1)$, the Professional Association of Nurses $(n=2)$, the Health and Youth Care Inspectorate $(n=2)$, and Nursing Home Organizations $(n=4)$. When consensus could not be reached within the research team, the topic of discussion was presented to the panel of experts. Eventually, these iterative steps have resulted in the development of the INDividually EXperienced QUAlity of LTC (INDEXQUAL) framework (Figure 1, Table 1).

INDEXQUAL aims to provide a framework describing the process of experienced quality of LTC by focusing on the care recipient's experiences with care services and factors occurring prior to, during, and after this experience, within a certain context. The framework presents a process that starts with a personal need and ends after an experience. In the after experience, a differentiation could be made between a variety of care recipient groups, including moving out of 1 particular LTC setting (eg, nursing home) to another type of care setting (eg, home care), remaining in the LTC setting, or passing away. The framework is a global representation that allows for adaptation to a specific LTC setting, timing, and population.

Two principles underlie the development of INDEXQUAL. First, INDEXQUAL assumes that care provision is a form of service delivery and, therefore, a process that consists of a before, during, and after phase. ${ }^{17}$ Second, INDEXQUAL places relationship-centered care at the core of care experiences, emphasizing that all relationships within the caring process need to be considered and not solely the care recipients. $^{27,37}$ It assumes that care experiences are mainly influenced by the interactions throughout the caring process, especially within LTC provision, which is more often focused on care and less on cure. ${ }^{28}$

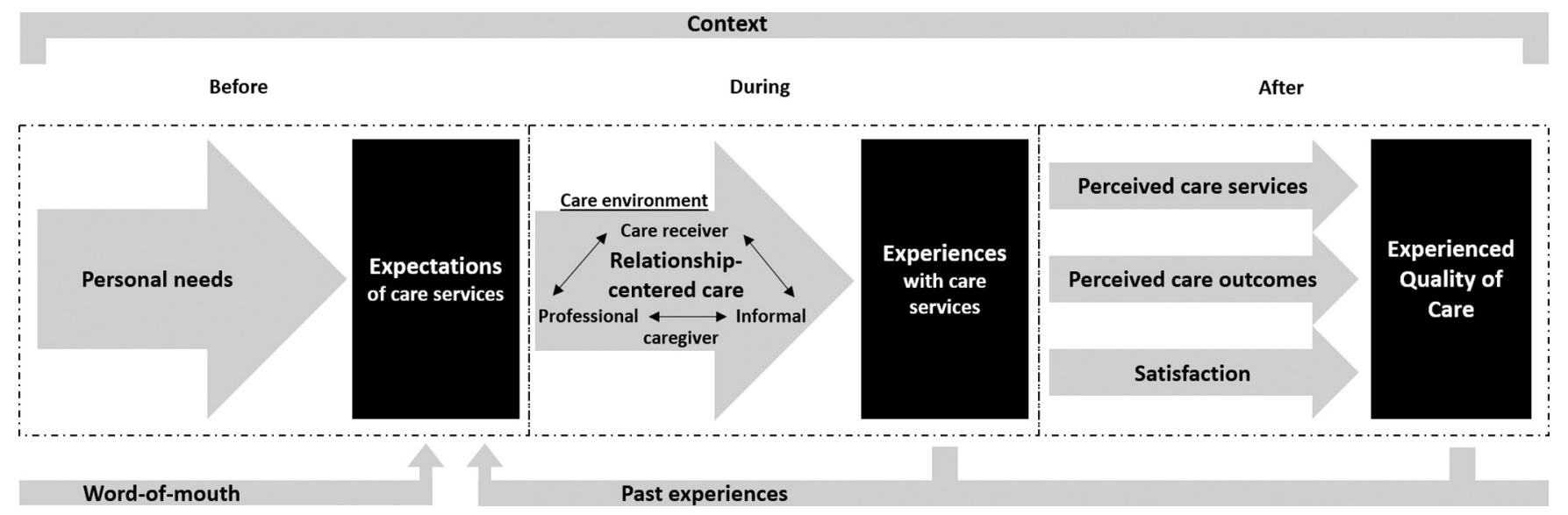

Fig. 1. A Framework of Individually Experienced Quality of LTC (INDEXQUAL). 
Table 1

Overview and Definitions of Individual Components From the INDEXQUAL Framework

\begin{tabular}{|c|c|c|}
\hline Concept & Description & Examples of Themes, Indicators, and/or Tools to Assess \\
\hline Context & $\begin{array}{l}\text { Care receiver characteristics and the setting in which care is } \\
\text { delivered. }\end{array}$ & $\begin{array}{l}\text { - Interpersonal environment: description of care recipient (ie, } \\
\text { age, sex, ethnicity, health status) } \\
\text { - Organizational environment [ie, type of care organization } \\
\text { (nursing home, home care, rehabilitation care)]; size; skill } \\
\text { mix; available facilities and supportive organizational } \\
\text { systems }\end{array}$ \\
\hline \multicolumn{3}{|l|}{ Expected Care Services } \\
\hline Personal care needs & $\begin{array}{l}\text { In the LTC setting, care needs can be placed into Nolan's senses } \\
\text { framework: security, continuity, belonging, significance, } \\
\text { purpose, and fulfilment. }\end{array}$ & $\begin{array}{l}\text { - Security - to feel safe physically, psychologically, } \\
\text { existentially } \\
\text { - Belonging - to feel part of a valued group, to maintain or } \\
\text { form important relationships } \\
\text { - Continuity - to be able to make links between the past, } \\
\text { present, and future } \\
\text { - Purpose - to enjoy meaningful activity, to have valued goals } \\
\text { - Achievement - to reach valued goals to satisfaction of self } \\
\text { and/or others } \\
\text { - Significance - to feel that you 'matter' and are accorded value } \\
\text { and status }\end{array}$ \\
\hline Past experience & $\begin{array}{l}\text { The client's previous exposure to a care service that is relevant } \\
\text { to the current service, and can shape predictions and } \\
\text { desires. }^{23}\end{array}$ & $\begin{array}{l}\text { Factors related to the experience of care transition between } \\
\text { different care services, such as experiencing changes of } \\
\text { significant relationships, moving from familiar to unknown } \\
\text { environments and cultures, being prepared for transfer, and } \\
\text { achieving responsibility. }^{24}\end{array}$ \\
\hline Word of mouth & $\begin{array}{l}\text { Personal and sometimes nonpersonal statements made by } \\
\text { parties other than the care organization or care receivers } \\
\text { themselves. They convey to care receivers what the service } \\
\text { will be like (ie, what they can expect). It is perceived as } \\
\text { unbiased and tends to be quite important in care services } \\
\text { because services are difficult for care receivers to evaluate } \\
\text { prior to purchasing and directly experiencing them. }\end{array}$ & $\begin{array}{l}\text { All information received from experts about the type of care } \\
\text { delivery, including reviews from other care receivers, friends, } \\
\text { and family, such as reviews on Yelp. }{ }^{23,26}\end{array}$ \\
\hline \multicolumn{3}{|l|}{ Experienced Care Services } \\
\hline Care environment & The direct environment influencing the care experience. ${ }^{27}$ & $\begin{array}{l}\text { Shared decision-making; effective staff relationships, power } \\
\text { sharing, potential for innovation and risk taking, and the } \\
\text { physical (home-like) environment. }\end{array}$ \\
\hline Relationship-centered care & $\begin{array}{l}\text { A framework that conceptualizes care. It focusses on the } \\
\text { influence of the nature and quality of relationships in the } \\
\text { process and outcomes of care services. }\end{array}$ & $\begin{array}{l}\text { Observations with for example the Maastricht Observation in } \\
\text { Daily Living tool assessing activities, physical environment, } \\
\text { social interaction and emotional well-being }{ }^{29} \text { or Dementia } \\
\text { Care Mapping. }^{30}\end{array}$ \\
\hline \multicolumn{3}{|l|}{ Experienced Quality of Care } \\
\hline Perceived care services & $\begin{array}{l}\text { The care receiver's assessment of what happened and how it } \\
\text { happened. }{ }^{31} \text { It is the impact of the process of the care on the } \\
\text { care receiver's experience. This can include relational aspects, } \\
\text { assessing the experience of the relationships during treatment } \\
\text { (ie, feeling heard) and functional aspects, assessing more } \\
\text { practical issues (ie, available facilities). }{ }^{32}\end{array}$ & $\begin{array}{l}\text { Consumer Assessment of Healthcare Providers and Systems } \\
\text { survey, includes indicators on ie, food quality, environment, } \\
\text { safety, pain management, staff skills, and choice. }{ }^{33} \\
\text { Picker Patient Experience Questionnaire, includes indicators on } \\
\text { ie, information and education, coordination of care, physical } \\
\text { comfort, emotional support, respect for patient preferences, } \\
\text { involvement of family and friends, and continuity and } \\
\text { transition. }^{34}\end{array}$ \\
\hline Perceived care outcomes & The care receiver's view on his or her health status. ${ }^{32}$ & $\begin{array}{l}\text { Health status outcomes, such as health-related quality of life } \\
\text { and improvement in health status measured by disease- } \\
\text { specific instruments. }\end{array}$ \\
\hline Satisfaction & $\begin{array}{l}\text { The gap between expectations and experiences, seen as an } \\
\text { evaluative, affective, or emotional response. }{ }^{35} \text { It expresses } \\
\text { how a care service encounter made the care receiver feel. }{ }^{31}\end{array}$ & $\begin{array}{l}\text { Net promotor score measures customer experience on a 0-10 } \\
\text { scale. }^{36}\end{array}$ \\
\hline
\end{tabular}

\section{Expectations (Before)}

There are 2 types of expectations: adequate and desired. Adequate expectations are what is likely to happen and what a care recipient considers to be acceptable. Desired expectations are the services a care recipient hopes and desires to receive, in other words, what they feel a service should offer. ${ }^{23}$ The range between an adequate and desired expectation of LTC services is formed by 3 influences: personal needs, past experiences, and word of mouth, as adopted from the Service Quality (SERVQUAL) model. ${ }^{18}$ This is the most widely known model in the field of service sciences, describing experienced service quality from the customer's perspective. ${ }^{18}$ It recognizes the difference between expected services and perceived services, known as the gap representing customer satisfaction. ${ }^{23,38}$
Experienced quality of care starts with the occurrence of a personal need. Everyone has basic personal needs, and within relationship-centered care these are defined as the 6 basic senses: security, continuity, belonging, significance, purpose, and fulfilment. ${ }^{22}$ Underlying any care service, there is a need related to 1 or multiple of these senses. For example, the need to receive competent care can be placed in the sense of security, or the need to form meaningful and interactive relationships can be placed in the sense of belonging. Past experiences are the care recipient's previous exposures to a care service that are relevant to the current service and can shape predictions and desires. ${ }^{23}$ They can have a direct impact on what someone expects from a care service. Other people's past experiences can influence a care recipient's expectations by word of mouth. ${ }^{18}$ These are personal and sometimes nonpersonal statements made by 
parties other than the organization, such as care recipient reviews, friends and family. ${ }^{25}$ They express what the service will be like to care recipients (ie, what they can expect). Word of mouth is perceived as unbiased and has shown to be quite important in care services because services are difficult for consumers to evaluate prior to purchasing and directly experiencing them. ${ }^{25}$

\section{Experiences (During)}

Experiences with care services are defined as the sum of interactions across the care process, influencing the care recipient's perception within the organizational culture. ${ }^{39}$ The care environment influences the care experience, for example, by means of the level of shared decision-making and the physical aspects of the environment, such as a home-like atmosphere, privacy, noise, and cleanliness. ${ }^{27,40,41}$ During the actual experience with a care service in the care environment, interactions within the caring relationships can influence the experience. Caring relationships are defined as "human interactions grounded in caring processes, incorporating physical work (doing), interactions (being with), and relationships (knowing each other)." ${ }^{20}$ They are deemed necessary to provide high quality of care. ${ }^{20}$ How care is delivered and received is dependent on how we define ourselves and others within a network of relationships and social circumstances. ${ }^{28}$ In service sciences, this is portrayed as balanced centricity, implying that value is co-created by all involved stakeholders who each deserve satisfaction of their needs and wants. ${ }^{42}$ Relationships are the medium of care that should be based upon mutual respect, equity, and shared understanding. ${ }^{43}$ Family is considered an important player in LTC, as their involvement can influence the care recipient's experiences by means of, for example choice, community connection, and quality of life. ${ }^{44}$ Figure 1 presents the relationships in a triangle consisting of the care recipient, professional caregivers, and informal caregivers. This network of relationships can differ for each individual care recipient; however, the simplified visualization in the framework portrays the emphasis on the relationships between the involved players. Players in the caring relationships can each have a view on the experienced quality of care process from the care recipient's perspective because they are part of the experience. For example, a family member also has certain expectations and experiences with the care provided to their loved one, and this can influence the experienced quality of care results.

\section{Experienced Quality of LTC (After)}

After the experience, the care recipient makes a conscious or unconscious assessment by comparing his or her expectations with the actual experience, taking into consideration the gap between the experience and the reported experience. ${ }^{45}$ This leads to an evaluation of 3 aspects: perceived care services, perceived care outcomes, and satisfaction. $^{31,32}$ Within perceived care services, the process of the experience is evaluated by answering questions such as what happened and how it happened. ${ }^{31}$ This can include relational aspects, assessing the experience of the care relationships (ie, feeling heard) and functional aspects, and assessing more practical issues (ie, allocated caregiving time).$^{32}$ Within perceived care outcomes, the care recipient's health status is assessed, such as (health-related) quality of life, levels of pain, and other changes in the care recipient's health outcomes. ${ }^{32}$ Within satisfaction, the care recipient attaches an emotional response to the experience, expressing how the experience made him or her feel. ${ }^{31}$ It is considered to be the gap between expectations and experiences, seen as an evaluative, affective, or emotional response. ${ }^{35}$ Eventually, the sum of these evaluations contributes to the assessment of the overall experienced quality of LTC.

\section{Context}

Considering the framework presents the process of experiences from an individual care recipient's perspective, it needs to be taken into account that each individual within the care process has his or her own personal characteristics, such as age, sex, education, ethnicity, and social class. ${ }^{45,46}$ The framework has been developed within the LTC setting for older people. ${ }^{1}$ The individual characteristics and the LTC setting for older people in which care is delivered (ie, at home or in a nursing home) shape the context of an experience. ${ }^{20,21}$

\section{Example}

INDEXQUAL can be adapted to different settings, timings, and populations. For example, the framework can be adapted to people with dementia living in nursing homes for the remainder of their lives. In this case, the framework can focus on assessing the entire experience of living in the nursing home for a longer period of time. The method to assess the experience might be by means of observations, as care recipients cannot always express themselves anymore. $^{29,30}$ In addition, the position of the family in the triangle may gain more importance in this setting to support and voice the needs of the care recipient.

\section{Implications for Practice, Policy, and/or Research}

INDEXQUAL presents a framework of a care recipient's journey, including the expectations, experiences, and assessment of quality of LTC in terms of perceived care services, care outcomes, and satisfaction. INDEXQUAL has been based on theory and the next step is to validate it in practice. The framework was developed for the LTC setting for older people, however, it may be applicable for other LTC settings as well. Currently, there is an occurring trend focused on the importance of relationships within care delivery. ${ }^{47}$ INDEXQUAL can provide insight into the care process as experienced within these relationships (care recipient, professional caregiver, and informal caregiver). It can be used as a framework to select existing methods or develop a new method to assess how LTC provision is experienced.

The INDEXQUAL framework differs from existing frameworks and models because it incorporates knowledge from healthcare literature and service sciences literature from the care recipient's perspective. It is a dynamic framework presenting the process of experienced quality of care, highlighting the importance of relationships within this experience. The framework presents an overarching representation allowing flexibility to adapt to specific LTC settings, timing, and population. In addition, INDEXQUAL addresses quality of LTC not only from the physical, but also from the social and emotional, aspects of care. This is in line with the growing focus on assessing more than standardized quality indicators and assessing the care recipient's experiences as well. Perceived care processes assess what happened and how it happened, perceived care outcomes assess the care recipient's self-reported health status, and satisfaction assesses how the experience made the care recipient feel. ${ }^{23,31,48}$ The sum of these results provides a more holistic view on how care provision is experienced. INDEXQUAL can serve as a framework for quality monitoring, improvement, and transparency.

\section{Acknowledgments}

All 7 authors made substantial contributions to the manuscript and approved the final version. Each individual author contributed to the development of the conceptual framework. All authors had a role in critically revising the article on its scholarly content. The researchers thank Prof Dr. Anna Beurskens, Dr. Bram de Boer, and Dr. Theresa Thoma-Lürken for their support with this research. The researchers 
also thank all experts that have contributed to the development and critical review of the INDEXQUAL framework.

\section{References}

1. OECD/EU. A Good Life in Old Age? Paris: OECD Publishing; 2013.

2. World Health Organisation. World report on ageing and health. Luxembourgh; 2015.

3. Rosher RB, Robinson S. Impact of the Eden alternative on family satisfaction. J Am Med Dir Assoc 2005;6:189-193.

4. Brownie S, Nancarrow S. Effects of person-centered care on residents and staff in aged-care facilities: A systematic review. Clin Intervent Aging 2013;8: $1-10$.

5. Snoeren MM, Janssen BM, Niessen TJ, et al. Nurturing cultural change in care for older people: Seeing the cherry tree blossom. Health Care Analysis 2016;24: 349-373.

6. McColl-Kennedy JR, Snyder H, Lars Witell ME, et al. The changing role of the health care customer: Review, synthesis and research agenda. J Service Manage 2017:28(1):2-33.

7. Shura R, Siders RA, Dannefer D. Culture change in long-term care: Participatory action research and the role of the resident. Gerontologist 2011;51:212-225.

8. Donabedian A. Evaluating the quality of medical care. The Milbank memorial fund quarterly 1966;44:166-206.

9. Institute of Medicine. Chapter 1. Health, Health Care, and Quality of Care. In: Lohr KN, editor. Medicare: A Strategy for Quality Assurance:Volume 1. Washington, DC: National Academies Press; 1990.

10. Donabedian A. The quality of care. How can it be assessed? JAMA 1988;260: 1743-1748

11. Castle NG, Ferguson JC. What is nursing home quality and how is it measured? Gerontologist 2010;50:426-442.

12. Huber M, Knottnerus JA, Green L, et al. How should we define health? BM 2011;343:d4163.

13. Huber M, van Vliet M, Giezenberg M, et al. Towards a 'patient-centred' operationalisation of the new dynamic concept of health: A mixed methods study. BMJ Open 2016;6:e010091.

14. Berwick DM. Medical associations: Guilds or leaders? Either play the role of victim or actively work to improve healthcare systems. BMJ 1997;314:1564.

15. Triemstra M, Winters S, Kool RB, et al. Measuring client experiences in longterm care in the Netherlands: A pilot study with the Consumer Quality Index Long-term Care. BMC Health Serv Res 2010;10:95.

16. Weldring T, Smith SM. Article Commentary: Patient-Reported Outcomes (PROs) and Patient-Reported Outcome Measures (PROMs). Health Services Insights 2013;6:S11093.

17. Voorhees CM, Fombelle PW, Gregoire Y, et al. Service encounters, experiences and the customer journey: Defining the field and a call to expand our lens. J Bus Res 2017;79:269-280.

18. Parasuraman A, Zeithaml VA, Berry LL. A conceptual model of service quality and its implications for future research. J Marketing 1985;49:41-50.

19. Goffin K, Mitchell R. Innovation management: Effective strategy and implementation. United Kingdom: Macmillan Education; 2016.

20. Duffy JR, Hoskins LM. The quality-caring model: Blending dual paradigms. ANS Adv Nurs Sci 2003:26:77-88.

21. McCormack B, McCance TV. Development of a framework for person-centred nursing. J Adv Nurs 2006;56:472-479.

22. Nolan M, Brown J, Davies S, et al. The senses framework: Improving care for older people through a relationship-centred approach. Getting Research into Practice (GRiP) Report No 2. University of Sheffield; 2006.

23. Parasuraman A, Zeithaml VA, Berry LL. SERVQUAL: A multiple-item scale for measuring customer perceptions of service quality. J Retailing 1988;6:12-40.
24. Fegran L, Hall EO, Uhrenfeldt L, et al. Adolescents' and young adults' transition experiences when transferring from paediatric to adult care: A qualitative metasynthesis. Int J Nurs Studies 2014;51:123-135.

25. Zeithaml VA, Berry LL, Parasuraman A. The nature and determinants of customer expectations of service. J Acad Marketing Sci 1993;21:1-12.

26. Johari K, Kellogg C, Vazquez K, et al. What consumers say about nursing homes in online reviews. Gerontologist 2018;58:e273-e280.

27. McCormack B, Roberts T, Meyer J, et al. Appreciating the 'person' in long-term care. Int J Older People Nurs 2012;7:284-294.

28. Soklaridis S, Ravitz P, Nevo GA, et al. Relationship-centred care in health: A 20year scoping review. Patient Exp J 2016;3:130-145.

29. de Boer B, Beerens HC, Zwakhalen SM, et al. Daily lives of residents with dementia in nursing homes: Development of the Maastricht electronic daily life observation tool. International Psychogeriatr 2016;28:1333-1343.

30. Brooker DJ, Surr C. Dementia Care Mapping (DCM): Initial validation of DCM 8 in UK field trials. Int J Geriatr psychiatry 2006;21:1018-1025.

31. LaVela SL, Gallan AS. Evaluation and measurement of patient experience. Patient Exp J 2014;1:36.

32. Kingsley C, Patel S. Patient-reported outcome measures and patient-reported experience measures. BJA Educ 2017;17:137-144.

33. Agency for Healthcare Research and Quality. CAHPS: Consumer Assessment of Healthcare Providers and Systems; Available at: http://www.cahps.ahrq.gov. Accessed February 15, 2019.

34. Jenkinson C, Coulter A, Bruster S. The Picker Patient Experience Questionnaire: Development and validation using data from in-patient surveys in five countries. Int Jr Qual Health Care 2002;14:353-358.

35. Oliver RL, DeSARBO WS. Processing of the satisfaction response in consumption: A suggested framework and research propositions. J Consumer Satisfaction, Dissatisfaction and Complaining Behav 1989;2:1-16.

36. Reichheld FF. The one number you need to grow. Harvard Bus Rev 2003;81: 46-54. 124.

37. Pew-Fetzer Task Force, Tresolini CP. Health professions education and relationship-centered care: Report. Pew Health Professions Commission, UCSF Center for the Health Professions; 1994.

38. Kulašin D, Fortuny-Santos J. Review of the SERVQUAL concept. The 4th Research/expert Conference with International Participation, In Macau. 2005, p 133-137.

39. Wolf JA, Niederhauser V, Marshburn D, et al. Defining Patient Experience. Patient Exp J 2014;1:7.

40. Chan J, Beard RL, Lyons W, et al. Factors that influence end-of-life care in nursing homes: The physical environment, inadequate staffing, and lack of supervision. Gerontologist 2003;43:76-84.

41. Mahmood A, Chaudhury H, Valente M. Nurses' perceptions of how physical environment affects medication errors in acute care settings. Appl Nurs Res 2011;24:229-237.

42. Gummesson E. Extending the service-dominant logic: From customer centricity to balanced centricity. J Acad Marketing Sci 2008;36: $15-17$.

43. Adams T, Clarke CL. Dementia care: Developing partnerships in practice. London: Bailliere Tindall Limited; 1999.

44. Gaugler JE. Family involvement in residential long-term care: A synthesis and critical review. Aging Mental Health 2005;9:105-118.

45. Sandager M, Freil M, Knudsen JL. Please tick the appropriate box: Perspectives on patient reported experience. Patient Exp J 2016;3:63-79.

46. Chow A, Mayer EK, Darzi AW, et al. Patient-reported outcome measures: The importance of patient satisfaction in surgery. Surgery 2009;146 435-443.

47. McCormack B, van Dulmen S, Eide H, et al. Person-centred healthcare research. Hoboken, NJ: Wiley; 2017.

48. Cronin JJ, Taylor SA. Measuring service quality: A reexamination and extension. J Marketing 1992;56:55-68. 


\section{Appendix 1. Additional Literature Used in Model Development but Not Cited}

This special article presents the final selection of core publications that were used to compose the INDEXQUAL framework. Behind the development of this framework lies a broad literature review of experienced quality of care from the care recipient's perspective. There is a secondary list of articles that contributed to the insights in this special article, but were not the primary contributors to the final framework. ${ }^{1-55}$ Reasons for exclusion were that these articles (1) did not focus on the care receiver's perspective; (2) focused on quality of life instead of quality of care; (3) presented specific outcomes or themes related to a specific setting or construct; (4) presented an adaptation of an existing model; or (5) did not present a model, framework or theory of quality of care or care experiences.

\section{References}

1. Alonazi WB, Thomas SA. Quality of care and quality of life: Convergence or divergence? Health Serv Insights 2014;7:1-12.

2. Babakus E, Mangold WG. Adapting the SERVQUAL scale to hospital services: An empirical investigation. Health Serv Res 1992;26:767-786.

3. Beach MC, Inui T. Relationship-centered care. A constructive reframing. J Gen Intern Med 2006:21:S3-S8.

4. Beattie M, Murphy DJ, Atherton I, et al. Instruments to measure patient experience of healthcare quality in hospitals: A systematic review. Syst Rev 2015;4:97.

5. Beerens HC. Adding Life to Years: Quality of Life of People With Dementia Receiving Long-term Care. Maastricht, the Netherlands: Hanneke Beerens; 2016.

6. Bird M, Anderson K, MacPherson S, et al. Do interventions with staff in longterm residential facilities improve quality of care or quality for life people with dementia? A systematic review of the evidence. Int Psychogeriatr 2016; 28:1937-1963.

7. Bjerregaard K, Haslam SA, Mewse A, et al. The shared experience of caring: A study of care-workers' motivations and identifications at work. Ageing Soc 2017:37:113-138.

8. Bjertnaes OA, Sjetne IS, Iversen HH. Overall patient satisfaction with hospitals: Effects of patient-reported experiences and fulfilment of expectations. BMJ Qual Saf 2012;21:39-46.

9. Bradshaw SA, Playford ED, Riazi A. Living well in care homes: A systematic review of qualitative studies. Age Ageing 2012;41:429-440.

10. Brod M, Stewart AL, Sands L, et al. Conceptualization and measurement of quality of life in dementia: The Dementia Quality of Life Instrument (DQoL). Gerontologist 1999;39:25-35.

11. Brooker D. Person-Centred Dementia Care: Making Services Better. London: Jessica Kingsley Publishers; 2006.

12. Brownie S, Nancarrow S. Effects of person-centered care on residents and staff in aged-care facilities: A systematic review. Clin Interv Aging 2013;8:1-10.

13. Campbell SM, Roland MO, Buetow SA. Defining quality of care. Soc Sci Med 2000;51:1611-1625.

14. Care Alliance Ireland. Literature Review on the Relationship Between Family Carers and Home Care Support Workers. Dublin, Ireland: Care Alliance Ireland; 2014.

15. Carr AJ, Gibson B, Robinson PG. Measuring quality of life: Is quality of life determined by expectations or experience? BMJ 2001;322:1240-1243.

16. Carr AJ, Higginson IJ. Are quality of life measures patient centred? BMJ 2001; 322:1357-1360.

17. Chow A, Mayer EK, Darzi AW, et al. Patient-reported outcome measures: The importance of patient satisfaction in surgery. Surgery 2009:146:435-443.

18. Cooney A, Murphy K, O'Shea E. Resident perspectives of the determinants of quality of life in residential care in Ireland. J Adv Nurs 2009;65:1029-1038.

19. Cossette S, Cara C, Ricard N, et al. Assessing nurse-patient interactions from a caring perspective: Report of the development and preliminary psychometric testing of the Caring Nurse-Patient Interactions Scale. Int J Nurs Stud 2005;42: 673-686.

20. Cronin JJ, Taylor SA. Measuring service quality: A reexamination and extension. J Market 1992;56:55-68.

21. D'Astous V, Abrams R, Vandrevala T, et al. Gaps in understanding the experiences of homecare workers providing care for people with dementia up to the end of life: A systematic review. Dementia (London) 2019;18:970-989.
22. Dewar B, Nolan M. Caring about caring: Developing a model to implement compassionate relationship centred care in an older people care setting. Int J Nurs Stud 2013;50:1247-1258.

23. Garvin DA. What does "product quality" really mean? Sloan Manage Rev 1984; 26:25-43.

24. Gerteis M, Edgman-Levitan S, Daley J, Delbanco TL, editors. Through the Patient's Eyes: Understanding and Promoting Patient-Centered Care. San Francisco: Jossey-Bass; 1993.

25. Glass AP. Nursing home quality: A framework for analysis. J Appl Gerontol 1991;10:5-18.

26. Griffiths P. State of the Art Metrics for Nursing: A Rapid Appraisal. London: National Nursing Research Unit, King's College London; 2008.

27. Gronroos C. Service quality: The six criteria of good perceived service. Rev Bus 1988;9:10.

28. Gummesson E. Extending the service-dominant logic: From customer centricity to balanced centricity. J Acad Market Sci 2008;36:15-17.

29. Hudon C, Fortin M, Haggerty JL, et al. Measuring patients' perceptions of patient-centered care: A systematic review of tools for family medicine. Ann Fam Med 2011;9:155-164.

30. Jenkinson C, Coulter A, Bruster S, et al. Patients' experiences and satisfaction with health care: Results of a questionnaire study of specific aspects of care. Qual Saf Health Care 2002;11:335-339.

31. Kane RA. Long-term care and a good quality of life: Bringing them closer together. Gerontologist 2001;41:293-304.

32. Kane RA, Kling KC, Bershadsky B, et al. Quality of life measures for nursing home residents. J Gerontol A Biol Sci Med Sci 2003;58:240-248.

33. Kobayashi $\mathrm{H}$, Takemura Y, Kanda K. Patient perception of nursing service quality: An applied model of Donabedian's structure-process-outcome approach theory. Scand J Caring Sci 2011;25:419-425.

34. Kuis EE, Hesselink G, Goossensen A. Can quality from a care ethical perspective be assessed? A review. Nurs Ethics 2014;21:774-793.

35. Kulašin D, Fortuny-Santos J. Review of the SERVQUAL concept. Paper presented at: The 4th Research/expert Conference with International Participation. Macau; 2005.

36. Lee D. HEALTHQUAL: A multi-item scale for assessing healthcare service quality. Serv Bus 2017;11:491-516.

37. Marcoen A. Filial maturity of middle-aged adult children in the context of parent care: Model and measures. J Adult Dev 1995;2:125-136.

38. McColl-Kennedy JR, Snyder H, Lars Witell ME, et al. The changing role of the health care customer: Review, synthesis and research agenda. J Serv Manage 2017;28:2-33.

39. Mead N, Bower P. Patient-centredness: A conceptual framework and review of the empirical literature. Soc Sci Med 2000;51:1087-1110.

40. Miller D, Gray CS, Kuluski K, et al. Patient-centered care and patient-reported measures: Let's look before we leap. Patient 2015;8:293-299.

41. Morgan S, Yoder LH. A concept analysis of person-centered care. J Holist Nurs 2012;30:6-15.

42. Oliver RL, Swan JE. Consumer perceptions of interpersonal equity and satisfaction in transactions: A field survey approach. J Market 1989;53:21-35.

43. Oliver RL. Cognitive, affective, and attribute bases of the satisfaction response J Consum Res 1993;20:418-430.

44. Oliver RL. Customer satisfaction, Wiley International Encyclopedia of Marketing. John Wiley \& Sons, Ltd; 2010.

45. Pascoe GC. Patient satisfaction in primary health care: a literature review and analysis. Eval Program Plann 1983;6:185-210.

46. Rantz MJ, Mehr DR, Popejoy L, et al. Nursing home care quality: A multidimensional theoretical model. J Nurs Care Oual 1998:12:30-46, quiz 69-70.

47. de Rooij AH, Luijkx KG, Spruytte N, et al. Family caregiver perspectives on social relations of elderly residents with dementia in small-scale versus traditional long-term care settings in the Netherlands and Belgium. J Clin Nurs 2012;21:3106-3116.

48. Rosher RB, Robinson S. Impact of the Eden Alternative on family satisfaction. J Am Med Dir Assoc 2005;6:189-193.

49. Shah DR, Roland T, Parasuraman A, et al. The path to customer centricity. J Serv Res 2006;9:113-124.

50. Shippee TP, Henning-Smith C, Kane RL, et al. Resident- and facility-level predictors of quality of life in long-term care. Gerontologist 2015:55:643-655.

51. Spreng RA, Mackoy RD. An empirical examination of a model of perceived service quality and satisfaction. J Retail 1996;72:201-214.

52. Tronto JC. Moral Boundaries: A Political Argument for an Ethic of Care. New York: Routledge; 1993.

53. Uman GC, Urman HN. Measuring consumer satisfaction in nursing home res idents. Nutrition 1997;13:705-707.

54. De Waele I, Van Loon J, Van Hove G, et al. Quality of life versus quality of care: Implications for people and programs. J Policy Pract Intellect Disabil 2005;2: 229-239.

55. Zubritsky C, Abbott KM, Hirschman KB, et al. Health-related quality of life: expanding a conceptual framework to include older adults who receive longterm services and supports. Gerontologist 2013;53:205-210. 